OPEN ACCESS

Edited by:

Letizia Polito,

University of Bologna, Italy

Reviewed by:

Sonia Ramos,

Consejo Superior de Investigaciones Científicas (CSIC), Spain

Marcella Manerba,

Italian Institute of Technology (IIT), Italy

*Correspondence:

Munish Puri

munish.puri@flinders.edu.au

Specialty section: This article was submitted to

Experimental Pharmacology and Drug Discovery,

a section of the journal

Frontiers in Pharmacology

Received: 19 June 2020 Accepted: 18 September 2020 Published: 28 October 2020

Citation:

Ajii PK, Walder K and Puri M (2020)

Combination of Balsamin and

Flavonoids Induce Apoptotic Effects in Liver and Breast Cancer Cells.

Front. Pharmacol. 11:574496. doi: 10.3389/fphar.2020.574496

\section{Combination of Balsamin and Flavonoids Induce Apoptotic Effects in Liver and Breast Cancer Cells}

\author{
Parminder K. Ajji ${ }^{1}$, Ken Walder ${ }^{2}$ and Munish Puri ${ }^{1,3^{*}}$ \\ 1 Centre for Chemistry and Biotechnology, Deakin University, Geelong, VIC, Australia, ${ }^{2}$ Centre for Molecular and Medical \\ Research, School of Medicine, Deakin University, Geelong, VIC, Australia, ${ }^{3}$ Centre for Marine Bioproducts Development, \\ College of Medicine and Public Health, Flinders University, Adelaide, SA, Australia
}

Flavonoids such as naringenin, quercetin, and naringin are known to exhibit anticancer properties. In this study, we examined the effects of these flavonoids on cell viability and apoptotic pathways of cancer cells, either singly or in combination with the type 1 ribosome inactivating protein, Balsamin. Treatment with flavonoids (naringenin, quercetin, and naringin) plus Balsamin for $48 \mathrm{~h}$ reduced HepG2 and MCF-7 cell viability, increased the activation of caspase- 3 and -8 , and induced apoptosis through up-regulation of pro-apoptotic genes and down-regulation of anti-apoptotic genes. Out of the three flavonoids tested, the Balsamin-Naringenin and Balsamin-Quercetin combinations appeared to be most effective compared to the Balsamin-Naringin combination. Balsamin combined with flavonoids also activated endoplasmic reticulum (ER)-stress-mediated apoptosis in breast cancer (MCF-7) cells, which was not activated by Balsamin treatment alone. These experimental results showed that Balsamin combined with flavonoids can reduce HepG2 and MCF-7 cells viability and induce apoptosis, which could be considered as a promising therapeutic approach to sensitize cells to Balsamin treatment, thereby improving its efficacy in breast or liver cancer therapy.

Keywords: bioactives, naringin, naringenin, quercetin, therapeutics, ribosome inactivating proteins

\section{INTRODUCTION}

Flavonoids are group of polyphenolic compounds found in fruits, vegetables, herbs, cereals, and dairy products (Cook and Samman, 1996). Flavonoids as a complementary medicine have attracted the attention of researchers due to their diverse pharmacological properties, including antioxidant, antibacterial, antiviral, antitumor, anti-atherosclerosis, antidiabetic, anti-inflammatory, antithrombogenic, hypolipidemic, and neuroprotective effects (Huang et al., 2016). Such biological diversity of flavonoids appears to be associated with their ability to regulate a number of cell signaling cascades, and could play a pivotal role in human health (Williams et al., 2004).

Of all the polyphenols known, naringenin (Nar) and its derivatives are known to possess strong antioxidant potential along with other biologically beneficial effects (Salehi et al., 2019). Nar is a flavone, a type of flavonoid that is abundantly found in citrus fruits (Puri et al., 2011). It is derived from the hydrolysis of the glycone form of flavanones, such as naringin (Figure 1) (Erlund, 2004). Naringin (Nir) is a flavanone glycoside found in grapes and citrus fruits. It consists of two sugar 


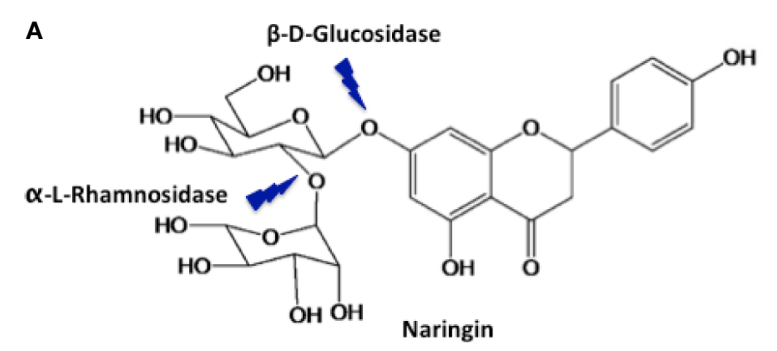<smiles>O=c1c(O)c(-c2ccc(O)c(O)c2)oc2cc(O)cc(O)c12</smiles>

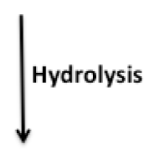

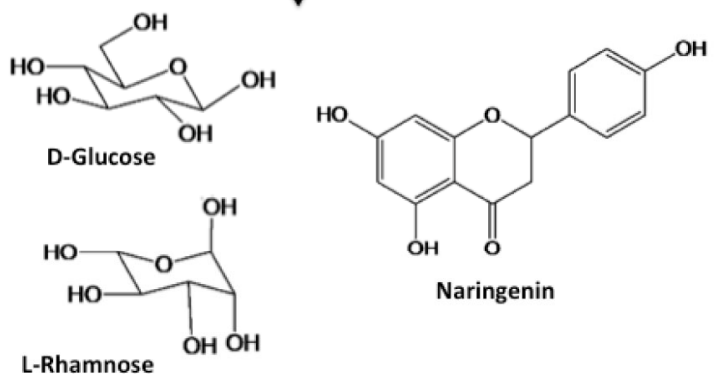

FIGURE 1 | Structure of naringin and its hydrolysed product naringenin (A), and quercetin (B).

units (glucose and rhamnose) attached to its aglycon portion, Nar, at the 7-carbon atom (Figure 1) (Puri et al., 2012; Alam et al., 2014). Studies have shown that both Nar and Nir exert a variety of common pharmacological effects including antioxidant, antiinflammatory, anticarcinogenic, and hepatoprotective effects (Bharti et al., 2014). Quercetin (Qu) is a flavonol, another type of flavonoid that is abundantly found in edible fruits and vegetables, and has also gained attention in human health. It consists of two aromatic rings connected via an oxygen containing heterocyclic ring (Figure 1) (Gibellini et al., 2011). Qu has reported health benefits similar to Nar and Nir, and it has also been used therapeutically in allergic conditions (such as asthma, hayfever, eczema and hives), arthritis, metabolic syndrome and mood disorders (Kelly, 2011).

Several studies have demonstrated that these flavonoids exhibit anticancer properties toward various cancers, including liver, breast, lung, colon, and bladder cancer (Park and M Pezzuto, 2012; Sharma et al., 2017). Nar inhibited the proliferation of breast cancer (MCF-7) cells by blocking insulin stimulated glucose uptake in GLUT4 (insulin responsive glucose transporter) expressing, insulin responsive MCF-7 cells. Nar blocked glucose uptake by impairing the activation of phosphoinositide3-kinase (P13K), a key regulator of insulin induced GLUT4 translocation, and inhibiting the phosphorylation of $\mathrm{p} 44 / \mathrm{p} 42$ mitogen-activated protein kinase (MAPK), a step essential for the insulin signaling pathway (Harmon and Patel, 2004). Nir induced apoptosis in breast cancer cells (MDA-MB-231 and BT549) by increasing the expression of p21 and decreasing the expression of survivin (inhibitor of apoptosis protein, IAP) and active $\beta$-catenine ( $\mathrm{Li}$ et al., 2013). Similarly, Qu supressed the expression of survivin and induced G0/G1 phase cell cycle arrest in breast cancer (MCF-7) cells (Deng et al., 2013). In the case of liver cancer (HepG2) cells, Qu induced apoptosis via inhibition of FASN (fatty acid synthase), a metabolic enzyme that is usually upregulated during early stages of tumorigenesis (Zhao et al., 2014). Nar and Nir induced apoptosis in HepG2 cells via mitochondrial mediated activation of caspase-9 and caspase-8 mediated proteolysis of Bid (Arul and Subramanian, 2013; Banjerdpongchai et al., 2016). This evidence suggests that the anti-cancer effects of these flavonoids involved various mechanisms, a desirable trait in cancer therapeutics.

Balsamin (Bal), a type I ribosome inactivating protein (RIP) from Momordica balsamina, exhibits potent anti-HIV activity (Puri et al., 2012). It blocks the replication of HIV by inhibiting the translation step, occurring prior to viral budding and release (Kaur et al., 2013). Our recent studies have shown that Bal exhibits DNase-like activity, and broad spectrum antimicrobial and antioxidant activity (Ajji et al., 2016). Further, in subsequent studies on the anti-proliferative effects of Bal on liver (HepG2 and H4IIE) and breast cancer (MCF-7 and BT549) cells, we showed that Bal induced apoptosis in liver cancer cells via increasing the expression of pro-apoptotic markers involved in mitochondrial mediated (caspase-3, Bax, Bid, Bad, and p53), death receptor mediated (caspase-3 and -8) and endoplasmic reticulum (ER)-stressmediated (GRP78 and CHOP) apoptotic pathways, with no effect observed in the expression of anti-apoptotic genes (Bcl-2 and $\mathrm{Bcl}-\mathrm{XL}$ ). However, in breast cancer cells, Bal increased the expression of pro-apoptotic markers and also simultaneously decreased the expression of anti-apoptotic genes, triggering 
mitochondrial mediated and death receptor mediated apoptosis. Interestingly, Bal did not activate the ER-stressmediated pathway in breast cancer cells, suggesting diverse mechanisms of apoptosis induction in different cancer cells (Ajji et al., 2017).

Bal and flavonoids (Nar, Nir, and Qu) appear to exert antitumor effects and induce apoptosis through similar mechanisms in liver (HepG2) and breast (MCF-7) cancer cells, therefore, we hypothesized that Bal-flavonoid (Nar, Nir, and Qu) combinations might have additive apoptotic effects on these cells. Thus, in this study, we examined the effect of co-treatment of Bal and three flavonoids, namely Nar, Nir, and Qu, on HepG2 and MCF-7 cells.

\section{MATERIALS AND METHODS}

\section{Chemicals, Reagents, and Kits}

Nar (purity $\geq 95 \%$ ), Nir (purity $\geq 95 \%$ ), and Qu (purity $\geq 95 \%$ ), trypsin, in vitro toxicology assay kit, Caspase-3 assay kit and Caspase- 8 assay kit were procured from Sigma-Aldrich (USA). RPMI and DMEM media, and FBS were purchased from Life Technologies Corporation (California, USA). Total RNA isolation kit was purchased from Qiagen (Hilden, Germany). CM Sepharose and Superdex 75 for Balsamin purification were procured from GE Healthcare (Buckinghamshire, UK). Reagents used for electrophoresis were purchased from Bio Rad Laboratories (California, USA). All other reagents were purchased from Sigma-Aldrich (USA) and were of analytical grade.

\section{Purification of Balsamin}

Balsamin was purified from Momordica balsamina seeds based on our earlier published method (Kaur et al., 2012). The seeds were powdered and homogenized in $50 \mathrm{ml}$ of $150 \mathrm{mM} \mathrm{NaCl}$. The slurry obtained was centrifuged at $12,000 \mathrm{~g}$ for $20 \mathrm{~min}$ at $4^{\circ} \mathrm{C}$. Following centrifugation, the proteins were precipitated from the supernatant with the addition of ammonium sulphate. The precipitate obtained after centrifugation was dissolved in $10 \mathrm{mM}$ phosphate buffer (PB), $\mathrm{pH} 6.5$, and dialysed against the same buffer. Following equilibration of a CM-Sepharose column with $\mathrm{PB}, \mathrm{pH} 6.5$, the dialysed sample was loaded onto the column and elution of unbound protein was carried out with $\mathrm{PB}, \mathrm{pH}$ 6.5. The bound proteins were eluted with $0.1-0.4 \mathrm{M} \mathrm{NaCl}$ in $\mathrm{PB}, \mathrm{pH}$ 6.5. The peak fractions containing the protein of interest (analyzed by SDS-PAGE) were pooled, concentrated and loaded onto a Superdex 75 column equilibrated with $\mathrm{PB}, \mathrm{pH}$ 6.5. The eluted fractions with the desired protein were pooled, concentrated, and further used for this study. The purified Bal was characterized by SDS-PAGE and protein concentration was determined by the Bradford method (Kaur et al., 2012).

\section{Cell Lines and Cell Culture}

Liver (HepG2) and breast (MCF-7) cancer cells lines were investigated. These cell lines were procured from the American Type Culture Collection (Rockville, MD, US). HepG2 and MCF-7 cells were maintained in RPMI and DMEM media supplemented with heat inactivated $10 \%$ FBS, respectively, in an environment of $5 \% \mathrm{CO}_{2}$ at $37^{\circ} \mathrm{C}$. These cells were proliferated in T-25 flasks until $80 \%$ confluence and split 1:10 and 1:4, separately, in culture dishes before experiments were performed.

\section{Treatment Groups}

For the cell viability assay, the treatment regimes given in Figure 2 were used. Based on empirical data, treatments highlighted in Figure 2 were selected for all other assays.

\section{Cell Viability Assay}

HepG2 and MCF-7 cells were seeded in 96 well plates in a seeding density of $\sim 1 \times 10^{4}$ cells/well for $24 \mathrm{~h}$. After incubation, the cells were exposed to the treatment regimes given in Figure 2 for $24 \mathrm{~h}$. Cell viability was then analyzed using an in vitro toxicology assay kit. MTT reagent was added to each well and the cells were incubated for $4 \mathrm{~h}$. The MTT formazon dye crystals formed during the experiment were dissolved in MTT solubilization solution and the absorbance was measured using a microplate reader (Bio-Rad, USA) at a wavelength of $570 \mathrm{~nm}$. All experiments were performed three times and results were expressed as mean \pm standard deviation.

\section{Morphology Assay}

Hep G2 and MCF-7 cells were seeded in 6-well plates in a seeding density of $\left(\sim 1 \times 10^{5}\right.$ cells/well for $24 \mathrm{~h}$. After $24 \mathrm{~h}$, the cells were treated with the treatments highlighted in Figure 2 for 48 h. Cell morphology was then examined using a light microscope.

\section{Caspase-3/-8 Activity Assay}

HepG2 and MCF-7 cells were seeded in 24 well plates in a seeding density of $6 \times 10^{4}$ cells/well) for $24 \mathrm{~h}$. After $24 \mathrm{~h}$, the cells were treated with treatments highlighted in Figure 2 for 48 h. After collecting and lysing the cells; caspase- 3 and caspase- 8 activity was determined immediately. The activity of caspase- 3 and caspase- 8 in triplicate was determined using caspase- 3 and caspase- 8 colorimetric assay kits according to the manufacturer's protocol. Briefly, $5 \mu \mathrm{l}$ of cell lysate and $1 \mathrm{X}$ assay buffer were added to the 96-well plate followed by caspase- 3 substrate (AcDEVD-pNA) and caspase-8 substrate (AcIETD-pNA) to each well, respectively. The plates were incubated at $37^{\circ} \mathrm{C}$ for $2 \mathrm{~h}$. Finally, the absorbance of pNA catalyzed by caspase- 3 and caspase-8, respectively were measured using microplate system at $405 \mathrm{~nm}$. All experiments were performed three times and results were expressed as mean \pm standard deviation.

\section{RNA Extraction and RT-PCR for Gene Expression Studies}

HepG2 and MCF-7 cells were seeded in 24 well plates in a seeding density of $6 \times 10^{4}$ cells/well for $24 \mathrm{~h}$. After incubation, the cells were treated with the treatments highlighted in Figure 2 for $48 \mathrm{~h}$. After treatment, total RNA was extracted using a Total RNA isolation kit (Qiagen) according to the protocol described by the manufacturer.

Maxima $\mathrm{H}$ minus first strand cDNA synthesis kit was used to synthesize first strand complementary DNA (cDNA) from each 

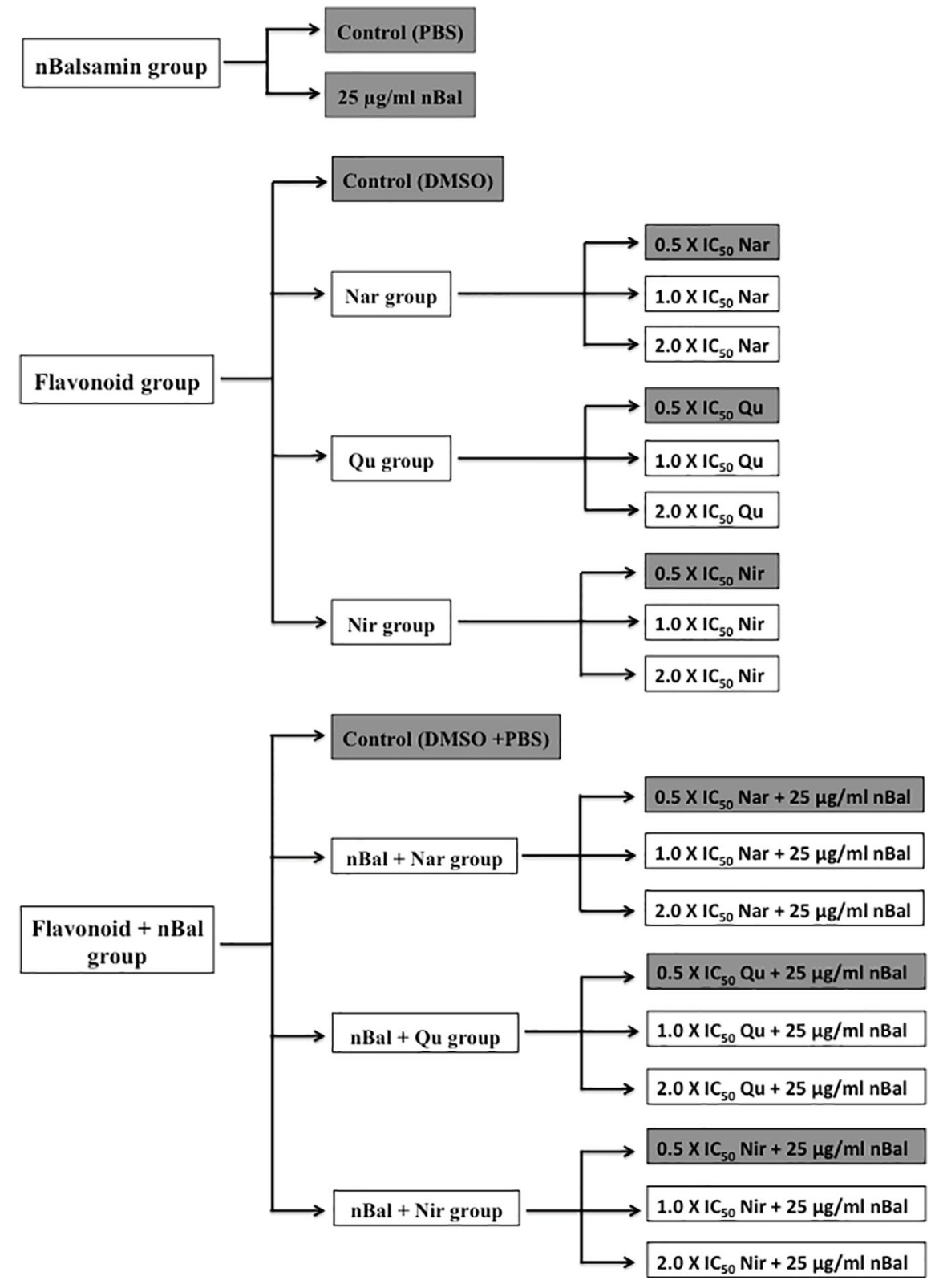

FIGURE 2 | Treatment regime used for the study (IC $\mathrm{C}_{50}$ values for Nar, Nir and Qu are $150 \mu \mathrm{M}, 20 \mu \mathrm{M}$ and $37 \mu \mathrm{M}$ respectively).

RNA sample. RT-PCR was carried out at $50^{\circ} \mathrm{C}$ for $30 \mathrm{~min}$, followed by $85^{\circ} \mathrm{C}$ for $5 \mathrm{~min}$ and $4^{\circ} \mathrm{C}$ for $5 \mathrm{~min}$, using the following primers sets: Bid: 5'- GCT GTA TAG CTG CTT CCA GTG TA -3’ (forward), 5’- GCT ATC TTC CAG CCT GTC TTC TC -3' (reverse); p53: 5’- CTG TCA TCT TCT GTC CCT TC -3' (forward), 5' - TGG AAT CAA CCC ACA GCT GCA -3' (reverse); Bax: 5'- CTG CAG AGG ATG ATT GCC G -3' (forward), 5' - TGC CAC TCG GAA AAA GAC CT -3' (reverse); Bad: 5'- GCA CAG CAA CGC AGA TGC -3' (forward), 5' - AAG TTC CGA TCC CAC CAG G -3' (reverse); Bcl2: 5'- GTG TGG AGA GCG TCA ACC G -3' (forward), 5'- CCT CTG TTT GAT TTC TCC TGG CT -3' (reverse); Bcl-XL: 5'- GAT CCC CAT
GGC AGC AGT AAA GCA AG -3' (forward), 5' - CCC CAT CCC GGA AGA GTT CAT TCA CT -3' (reverse); GRP78: 5'GGT GAC CTG GTA CTG CTT GAT G -3' (forward), 5' - CCT TGG AAT CAG TTT GGT CAT G -3' (reverse); CHOP: 5' - TGC TTC TCT GGC TTG GCT GAC -3’ (forward), 5’- CCA AGG GAG AAC CAG GAA ACG G -3' (reverse) (see Table 1).

PCR was carried out in a reaction mixture of $10 \mu$ under following conditions: $95^{\circ} \mathrm{C}$ for $7 \mathrm{~min}, 40$ cycles at $95^{\circ} \mathrm{C}$ for $30 \mathrm{~s}$ and $60^{\circ} \mathrm{C}$ for $1 \mathrm{~min}, 60^{\circ} \mathrm{C}$ for $60 \mathrm{~s}, 55^{\circ} \mathrm{C}-95^{\circ} \mathrm{C}$ (hold time: $1 \mathrm{~s}$, temperature increment after hold: $0.2^{\circ} \mathrm{C}$ ), and $20^{\circ} \mathrm{C}$ for $10 \mathrm{~s}$. All experiments were performed three times and results were expressed as mean \pm standard deviation. 
TABLE 1 | Primers used for RT-PCR.

\begin{tabular}{|c|c|c|}
\hline Gene & Forward primer $\left(5^{\prime}-3^{\prime}\right)$ & Reverse primer $\left(5^{\prime}-3^{\prime}\right)$ \\
\hline Bid & GCTGTATAGCTGCTTCCAGTGTA & GCTATCTTCCAGCCTGTCTTCTC \\
\hline p53 & СTGTCATCTTCTGTCCСTTC & TGGAATCAACCCACAGCTGCA \\
\hline Bax & CTGCAGAGGATGATTGCCG & TGCCACTCGGAAAAAGACCT \\
\hline Bad & GCACAGCAACGCAGATGC & AAGTTCCGATCCCACCAGG \\
\hline $\mathrm{Bcl} 2$ & GTGTGGAGAGCGTCAACCG & СCTCTGTITGATITCTCCTGGCT \\
\hline Bcl-XL & GATCCCCATGGCAGCAGTAAAGCAAG & CCCCATCCCGGAAGAGTTCATTCACT \\
\hline GRP78 & GGTGACCTGGTACTGCTTGATG & CCTTGGAATCAGTITGGTCATG \\
\hline CHOP & TGCTTCTCTGGCTTGGCTGAC & CCAAGGGAGAACCAGGAAACGG \\
\hline
\end{tabular}

\section{Statistical Analysis}

Data was analyzed using SPSS Statistics software version 22.0. Data was presented as the mean \pm SD for at least three independently performed experiments unless otherwise stated. The non-parametric test, Kruskal-Wallis $\mathrm{H}$ test, also known as one-way ANOVA on ranks, was used to compare the difference between two or more groups. Mann-Whitney $U$ test was used to compare the difference between two groups. Probability values with $\mathrm{p}<0.05$ were considered to be statistically significant.

\section{RESULTS}

\section{Growth Inhibitory Effects of Bal Combined With Flavonoids on Hepg2 and Mcf-7 Cells}

We first determined the effect of co-treatment of Bal $(25 \mu \mathrm{g} / \mathrm{ml})$ and flavonoids (Nar, Nir, or Qu) on the viability of HepG2 and MCF-7 cells using an in vitro toxicology assay kit. As shown in Figures 3A, B, the combination of Bal with low dose $\left(0.5 \times \mathrm{IC}_{50}\right.$ dose) of Nar appeared to inhibit the viability of HepG2 and MCF-7 cells compared to the cells treated with Bal and Nar alone. However, when the concentration of $\mathrm{Nar}\left(1.0 \times \mathrm{IC}_{50}\right.$ and $2.0 \times \mathrm{IC}_{50}$ ) was increased in combination with $\mathrm{Bal}$, no significant difference between the Bal-Nar and Nar treated groups was observed, suggesting that $0.5 \times \mathrm{IC}_{50}$ of Nar with Bal could be the most effective dose combination (Figures 3A, B).

Further, the trend appeared to be similar when HepG2 and MCF-7 were treated with Bal-Qu combinations (Figures 4A, B). However, when HepG2 and MCF-7 cell were co-treated with low dose $\left(0.5 \times \mathrm{IC}_{50}\right)$ of $\mathrm{Nir}$ and $\mathrm{Bal}$, the cell viability tended to decrease slightly compared to singly treated groups, however, the effect was not as prominent as observed with low dose $(0.5 \times$ $\mathrm{IC}_{50}$ ) of Nar or Qu with Bal. Further, when the concentration of Nir $\left(1.0 \times \mathrm{IC}_{50}\right.$ and $\left.2.0 \times \mathrm{IC}_{50}\right)$ was increased in combination with $\mathrm{Bal}$, no significant difference was observed in the groups treated with Bal-Nir combinations and Nir alone (Figures 5A, B). These results suggest that flavonoids (Nar, Nir, and Qu) could increase the anti-proliferative effects of Bal on HepG2 and MCF-7 cells, with low dose $\left(0.5 \times \mathrm{IC}_{50}\right)$ of flavonoids (Nar, Nir, and $\mathrm{Qu}$ ) found to be the most effective dose in combination with Bal. Therefore, we selected this flavonoid dose in combination with Bal for further study.

\section{Effect of Bal-Flavonoid Combination on the Morphology of HepG2 and MCF-7 Cells}

We next investigated if flavonoids (Nar, Nir, or Qu) could increase Bal induced apoptotic effects in HepG2 and MCF7 cells. For this, we examined the morphology of HepG2 and MCF-7 cells treated with combinations of Bal and Nar, Nir, or $\mathrm{Qu}$, and compounds alone under bright field microscopy. The results showed that apoptotic morphological changes, such as loss in cell connections, cell shrinkage, cell surface detachment, increased cytoplasmic density and more dead cells appeared to be more prominent in cells treated with Bal-flavonoid (Nar, Nir, or $\mathrm{Qu}$ ) combinations compared to single treatments (Figure 6).

\section{Caspase-3 and -8 Activity of Bal Combined With Nar, Nir, or Qu in HepG2 and MCF-7 Cells}

We further decided to evaluate whether flavonoids (Nar, Nir, and $\mathrm{Qu}$ ) increase caspase-mediated apoptotic effects in Bal treated HepG2 and MCF-7 cells. As shown in Figure 7A, Bal-Nar treatment tended to increase and appeared to have an additive effect on caspase- 3 and -8 activity in HepG2 and MCF-7 cells compared to $\mathrm{Bal}$ and Nar alone. Further, the trend appeared to be similar in HepG2 and MCF-7 cells treated with the Bal-Qu combination (Figure 7B). However, when HepG2 and MCF-7 cells were treated with the Bal-Nir combination, the caspase- 3 and -8 activity tended to increase as compared to Nir and Bal treatment alone, however, did not appear to have an additive effect (Figure 7C).

\section{Effect of Bal-Flavonoid Combinations on the Expression of Various Apoptotic Genes Involved in the Mitochondrial Cell Death Pathway}

We next studied if these flavonoids could increase Bal-induced mitochondrial apoptotic effects in HepG2 and MCF-7 cells. The qRT-PCR results showed that Bal-Nar treatment tended to increase and appeared to have an additive effect on the expression of Bax, Bid, Bad, and p53 compared to Bal treatment alone in HepG2 and MCF-7 cells. However, no significant difference was observed between the groups (Figure $\mathbf{8 A}$ ). Further, the trend appeared to be similar in HepG2 and MCF-7 cells treated with the Bal-Qu combination (Figure 8B), 

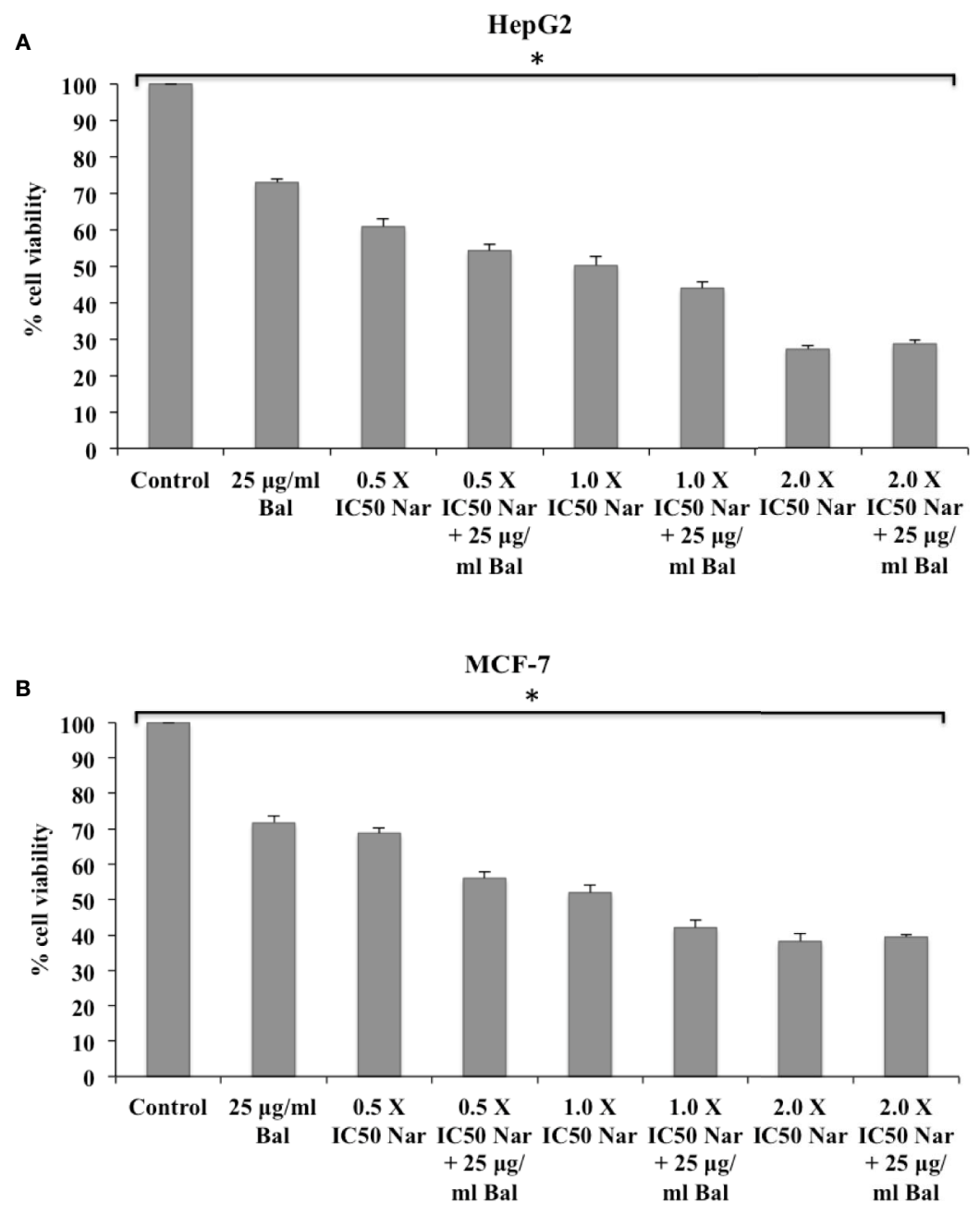

FIGURE 3 | Effect of Bal and Nar on the viability of HepG2 (A) and MCF-7 (B) cells compared with Bal. All values are mean \pm SD. SD, standard deviation; $n=3$; ${ }^{*} P<0.05$, Kruskal-Wallis $\mathrm{H}$ test.

suggesting that Nar and Qu increase Bal-induced apoptotic effect in HepG2 and MCF-7 cells.

In addition, the Bal-Nir combination appeared to increase the expression of Bax, Bid, Bad and p53 as compared Bal treatment alone in HepG2 and MCF-7 cells. However, the effect did not appear to be pronounced and additive compared to Bal-Nar and Bal-Qu treatment (Figure 8C), suggesting that the Bal-Nar and Bal-Qu combinations could be considered more effective than the Bal-Nir combination.

Further, we also evaluated the expression of anti-apoptotic genes ( $B c l-2$ and $B c l-X L)$ in HepG2 and MCF-7 cells treated with Bal-flavonoid (Nar, Nir, or Qu) combinations. The qRT-PCR results showed that Bal-Nar treatment tended to decrease the expression of $B c l-2$ and $B c l-X L$ compared to Bal and $\mathrm{Nar}$ treatment alone in HepG2 and MCF-7 cells, indicating a possible effect. However, no significant difference was observed between the groups (Figure 9A). Likewise, the trend appeared to similar, but less pronounced in HepG2 and MCF-7 cells treated with Bal-Qu and Bal-Nir combinations (Figures 9B, C).

\section{Effect of Bal-Flavonoid Treatment on the Expression of Genes Involved in Endoplasmic Reticulum-Stress- Mediated Apoptosis}

To investigate whether Bal-flavonoid treatment could increase Bal-induced ER stress in HepG2 cells and activate this pathway in breast cancer (MCF-7) cells, we evaluated the expression of CHOP and GRP78 in Bal-flavonoid (Nar, Nir, and Qu) treated HepG2 and MCF-7 cells.

The qRT-PCR results showed that the expression of GRP78 and $C H O P$ tended to increase in HepG2 cells treated with BalNar (Figure 10A), Bal-Qu (Figure 10B), and Bal-Nir (Figure 10C) combinations compared to Bal and flavonoids (Nar, Nir, and $\mathrm{Qu}$ ) treatment alone, indicating a possible additive effect of 

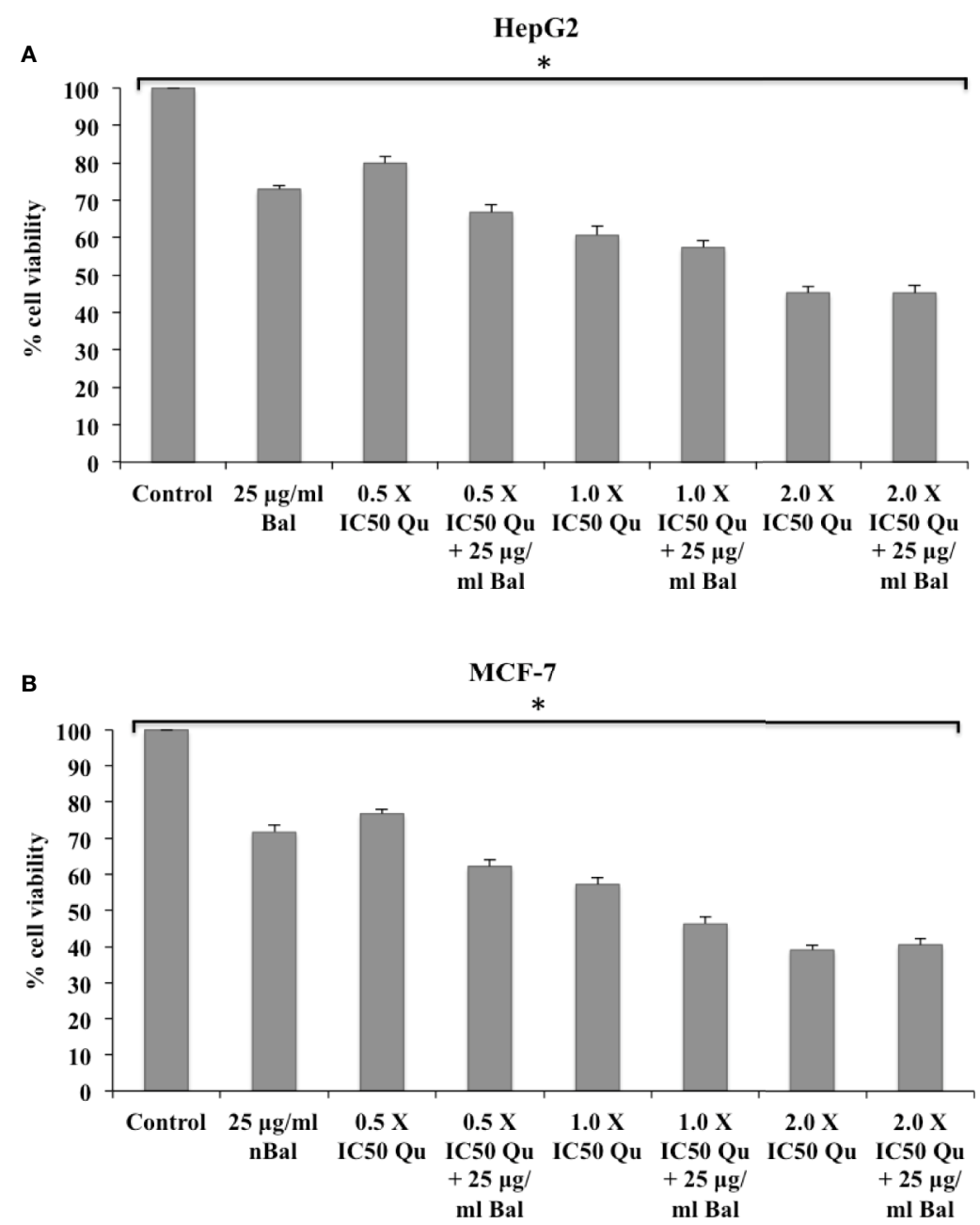

FIGURE 4 | Effect of Bal and Qu on the viability of HepG2 (A) and MCF-7 (B) cells compared with Bal. All values are mean \pm SD. SD, standard deviation; $n=3$; ${ }^{\star} \mathrm{P}<0.05$, Kruskal-Wallis $\mathrm{H}$ test.

co-treatment in HepG2 and MCF-7 cells. In the case of MCF-7 cells, Bal treatment alone did not increase the expression of GRP78 and CHOP. However, when Bal was combined with the flavonoids (Nar, Qu, and Nir), the expression tended to increase with respect to Bal alone, but did not increase significantly with respect to flavonoid ( $\mathrm{Nar}, \mathrm{Qu}$, and Nir) treatment alone, suggesting that the effect was entirely due to the presence of the flavonoid (Nar, Qu, or Nir) in the Bal-flavonoid combinations (Figures 10A-C).

\section{DISCUSSION}

The relationship between diet and cancer has been implicated in number of epidemiological studies (Ross, 2010). Vegetables, fruits, and cereals contain flavonoids that have antioxidant, anti-inflammatory and anticancer properties and Nar, Nir, and $\mathrm{Qu}$ are three such flavonoids that have been explored for their anti-proliferative effects toward various cancer cells. Nar, a natural flavone exhibits anti-tumor activity toward various tumor cell types including hepatoma (HepG2), breast cancer (MCF-7, HTB26 and HTB132), leukemia (K562), human epidermoid carcinoma (A431), colorectal cancer (SW1116 and SW837), and glioma cells (C6) (Harmon and Patel, 2004; Sabarinathan et al., 2011; Arul and Subramanian, 2013; Ahamad et al., 2014; Abaza et al., 2015; Li et al., 2015). Nir exerts antiproliferative effects on cancer cells such as breast cancer (MDA-MB-231 and BT549), liver cancer (HepG2), bladder cancer (5637), melanoma (A375), and glioblastoma (U87MG) (Kim et al., 2008; Guo et al., 2016; Li et al., 2016). $\mathrm{Qu}$ possesses antitumor activity against liver cancer (HepG2), breast cancer (MCF-7), leukemia (HL-60) and prostate cancer (DU-145 and PC-3) cells (Nair et al., 2004; Niu et al., 2011; Deng et al., 2013; Zhao et al., 2014).

Nar caused cell death via cytotoxic, genotoxic and apotosis effect on various cancer cell lines including HT-29, MCF-7 and 

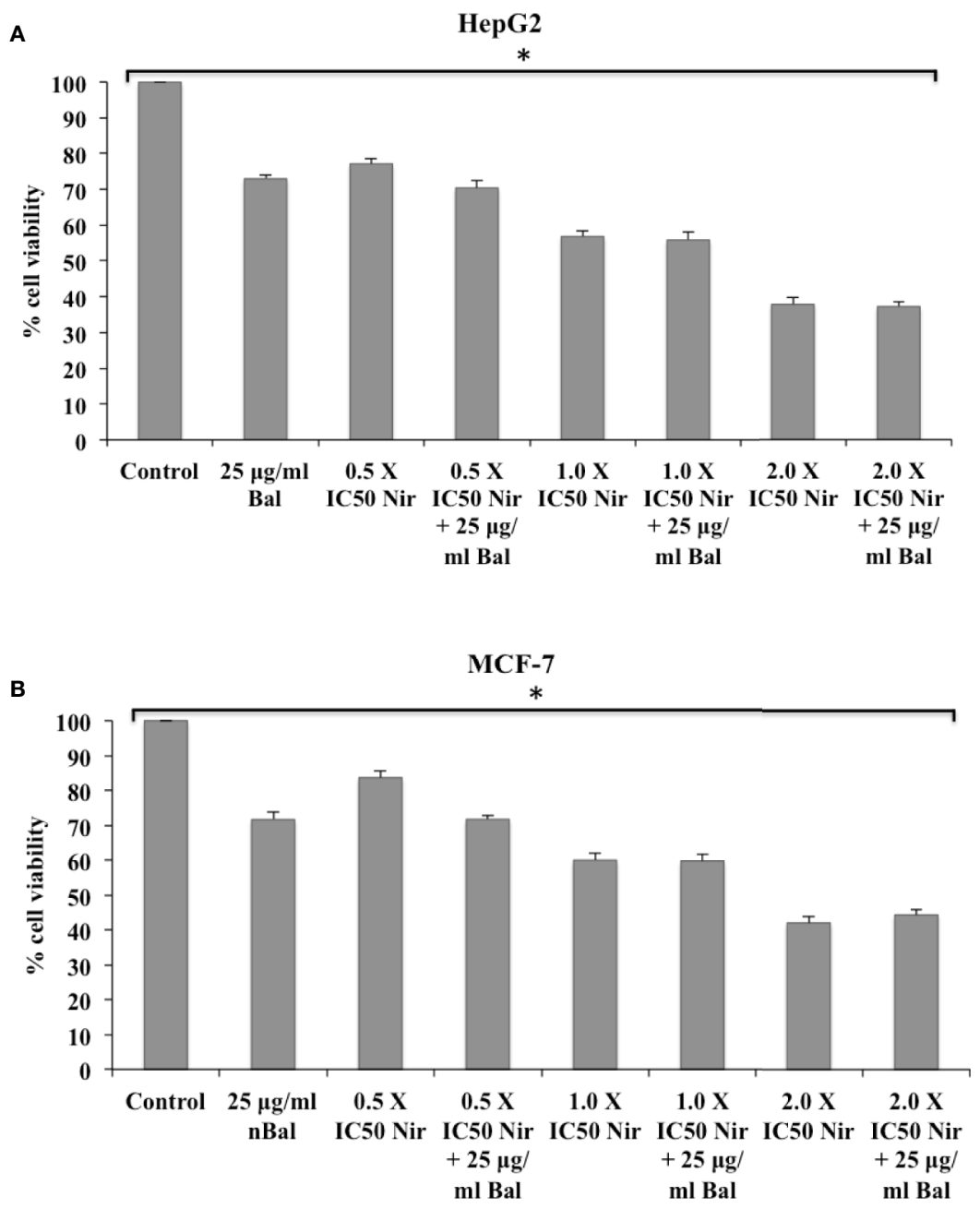

FIGURE 5 | Effect of Bal and Nir on the viability of HepG2 (A) and MCF-7 (B) cells compared with Bal. All values are mean \pm SD. SD, standard deviation; $\mathrm{n}=3$; ${ }^{\star} P<0.05$, Kruskal-Wallis $\mathrm{H}$ test.

PC-12 through the production of ROS and DNA damage in a dose dependent manner. However, the effects were found to be nominal in case of normal cell line, L-929 as the $\mathrm{IC}_{50}$ value of Nar for L-929 cell line could not be dertemined since the value was out of range (Kocyigit et el., 2016). Qu induced cytotoxicity in a dose dependent manner in leukemic (CEM and K562) and breast cancer (T47D and EAC) cells through DNA fragmentation, cell cycle arrest and activating intrinsic pathway of apoptosis. "However, normal cells dervived from human embryonic kidney (293T) as well as mouse embryonic fibroblast (MEF-1) were found to be insensitive to quercetin (Srivastava et al., 2016)" at similar concentrations able to induce death in carcinogenic cells (different works have already published this result).

Several studies have reported that flavonoids with antioxidant properties synergize the effect of chemotherapeutic drugs (Lewandowska et al., 2014). Qu increased cisplatin-induced apoptosis in human laryngeal cancer (Hep-2) cells (Kuhar et al., 2007). 4T1 breast tumor mice treated with Qu and doxorubicin demonstrated inhibition of tumor growth and reduction of doxorubicin side effects, leading to prolonged survival of the mice ( $\mathrm{Du}$ et al., 2010). Qu enhanced the antitumor effect of trichostatin-A, a novel anticancer drug, in human lung cancer cells through upregulation of p53 expression (Chan et al., 2013).

Our previous studies demonstrated that $\mathrm{Bal}$, a type I RIP isolated from Momordica balsamina, exhibits inhibitory effects toward HIV-1 replication (Kaur et al., 2013) and breast cancer cells, highlighting its potential as a therapeutic agent. It has previously been reported that Bal-induced apoptosis involved increases in caspase- 3 and caspase- 8 activity, cell cycle arrest at G-/S- phase, upregulation of Bax, Bid, and Bad, and downregulation of BCL-2 and BCL-XL (Ajji et al., 2017).

Since flavonoids (Nar, Nir, and $\mathrm{Qu}$ ) and Bal exerts anticancer effects, therefore the present study investigated the apoptotic effects of $\mathrm{Bal}$ in the presence of three flavonoids, namely Nar, Nir, and $\mathrm{Qu}$, on liver (HepG2) and breast cancer (MCF-7) cells. Cotreatment with $\mathrm{Bal}(25 \mu \mathrm{g} / \mathrm{ml})$ and flavonoids (Nar, Nir, or Qu) enhanced the anti-proliferative effects of Bal on HepG2 and 


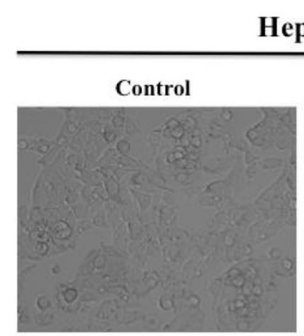

$0.5 \times$ IC50 Nar

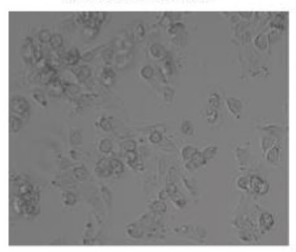

0.5 X IC50 Qu

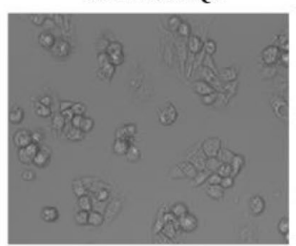

0.5 X IC50 Nir

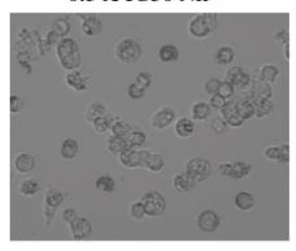

HepG2

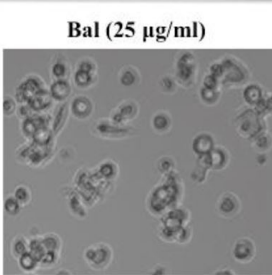

Bal + Nar

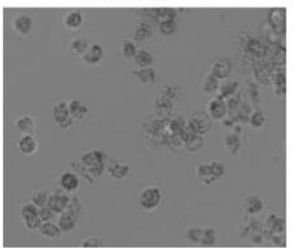

Bal + Qu

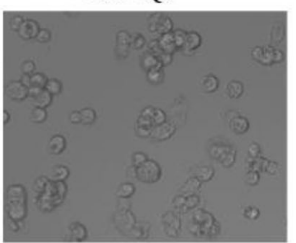

Bal + Nir

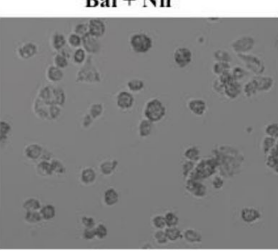

MCF-7

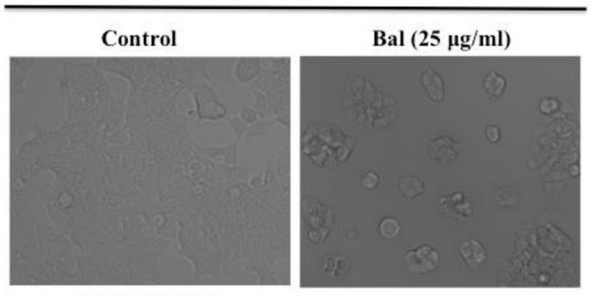

$0.5 \times$ IC50 Nar

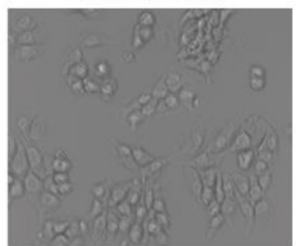

$0.5 \times$ IC50 Qu

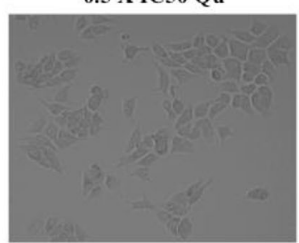

0.5 X IC50 Nir

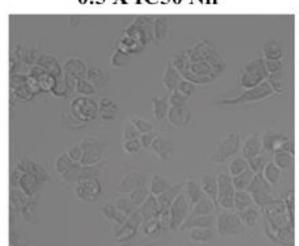

Bal + Nar

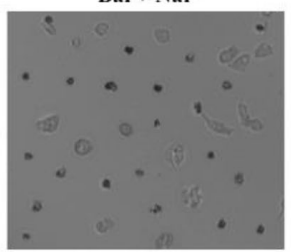

$\mathbf{B a l}+\mathbf{Q u}$

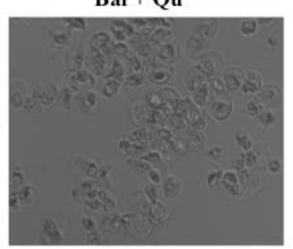

Bal + Nir

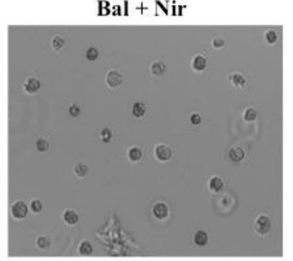

FIGURE 6 | Morphology of HepG2 and MCF-7 cells treated with Bal-Nar, Bal-Qu and Bal-Nir compared with Bal, Nar, Qu and Nir alone.

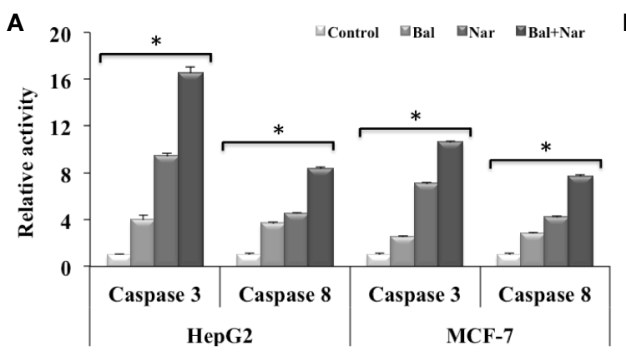

C

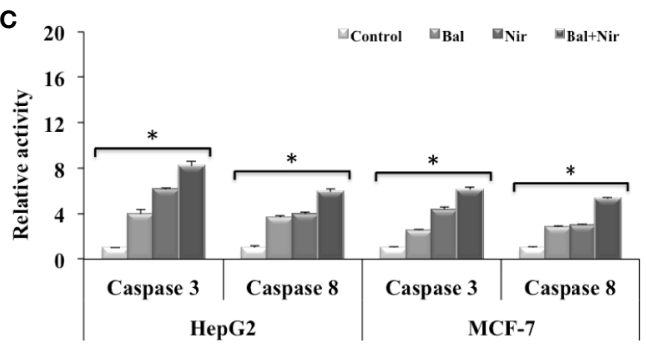

FIGURE 7 | Effect of Bal-Nar (A), Bal-Qu (B) and Bal-Nir (C) on caspase-3 and -8 activity compared with Bal in HepG2 and MCF-7 cells. All values are mean \pm SD. $\mathrm{SD}$, standard deviation; $n=3$; ${ }^{\star} P<0.05$, Kruskal-Wallis $H$ test. 
A

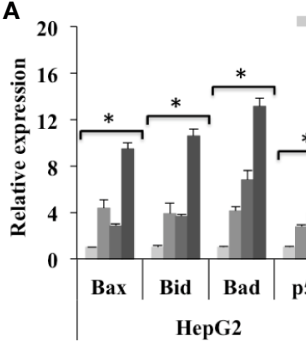

B

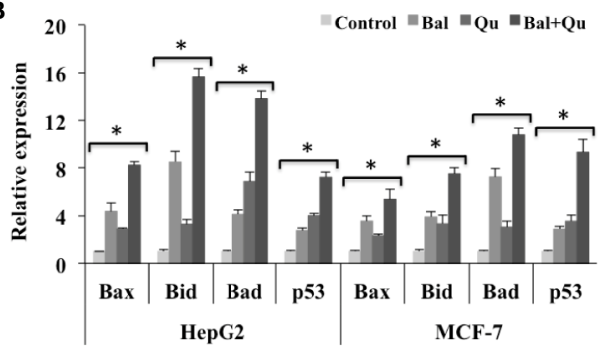

Control $=$ Bal $=$ Nir $\square$ Bal+Nir

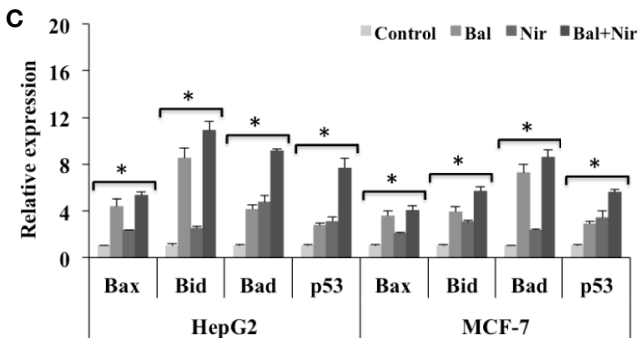

FIGURE 8 | Effect of Bal-Nar (A), Bal-Qu (B) and Bal-Nir (C) on the expression of pro-apoptotic genes, Bax, Bid, Bad and p53, compared with Bal in HepG2 and MCF-7 cells. All values are mean \pm SD. SD, standard deviation; $n=3 ;{ }^{*} P<0.05$, Kruskal-Wallis $H$ test.
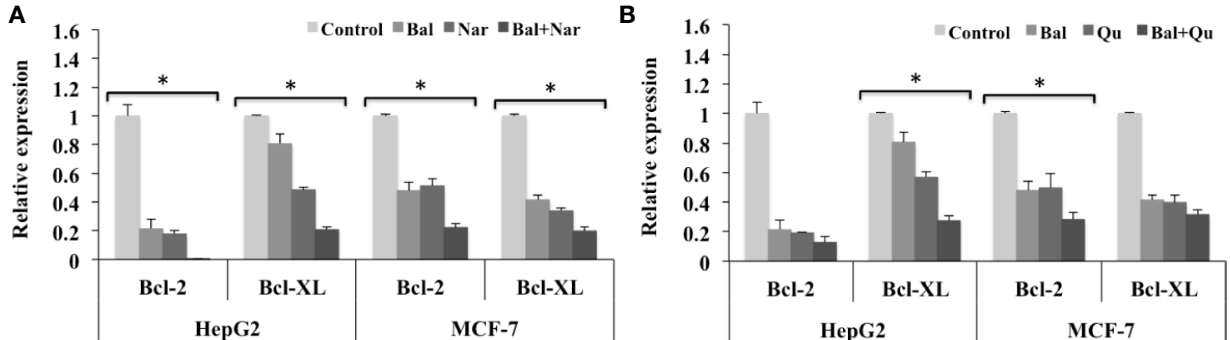

C

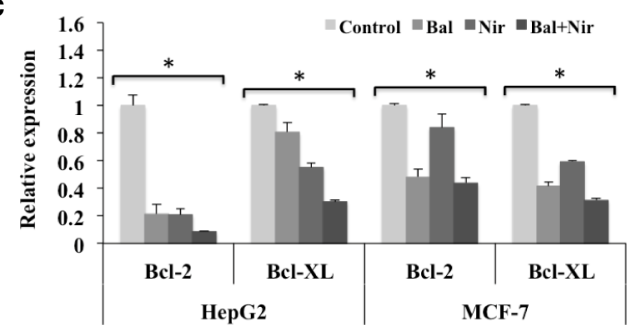

FIGURE 9 | Effect of Bal-Nar (A), Bal-Qu (B) and Bal-Nir (C) on the expression of anti-apoptotic genes, Bcl-2 and Bcl-XL, compared with Bal in HepG2 and MCF-7 cells. All values are mean $\pm \mathrm{SD}$. SD, standard deviation; $n=3 ;{ }^{*} P<0.05$, Kruskal-Wallis $\mathrm{H}$ test.

MCF-7 cells where low dose $\left(0.5 \times \mathrm{IC}_{50}\right)$ of flavonoids (Nar, Nir, and $\mathrm{Qu}$ ) in combination with $\mathrm{Bal}$ was found to be an effective dose as compared to other two doses $\left(1.0 \times \mathrm{IC}_{50}\right.$ and $\left.2.0 \times \mathrm{IC}_{50}\right)$ of Nar, Nir, or Qu, and henceforth the lowest dose $\left(0.5 \times \mathrm{IC}_{50}\right)$ of Nar, Nir, and Qu was selected in combination with Bal for further study. These doses were selected based on the empirical data; however, further investigations would be required to evaluate appropriate doses of $\mathrm{Bal}$ and flavonoids for alleviating liver and breast cancer in clinical trials
Flavonoids, such as Nar, Nir, and Qu are known to induce apoptosis in various cancer cells by regulating the expression of apoptotic markers (Arul and Subramanian, 2013; Banjerdpongchai et al., 2016). Apoptosis is a programmed and often energy dependent process that involves activation of caspases, a group of cysteine proteases, and a complex cascade of signals (Elmore, 2007). Flavonoids such as Nar, Nir, and Qu have been reported to activate caspase dependent apoptosis in cancer cells (Ramos, 2007). Nar and Nir induced apoptosis in 


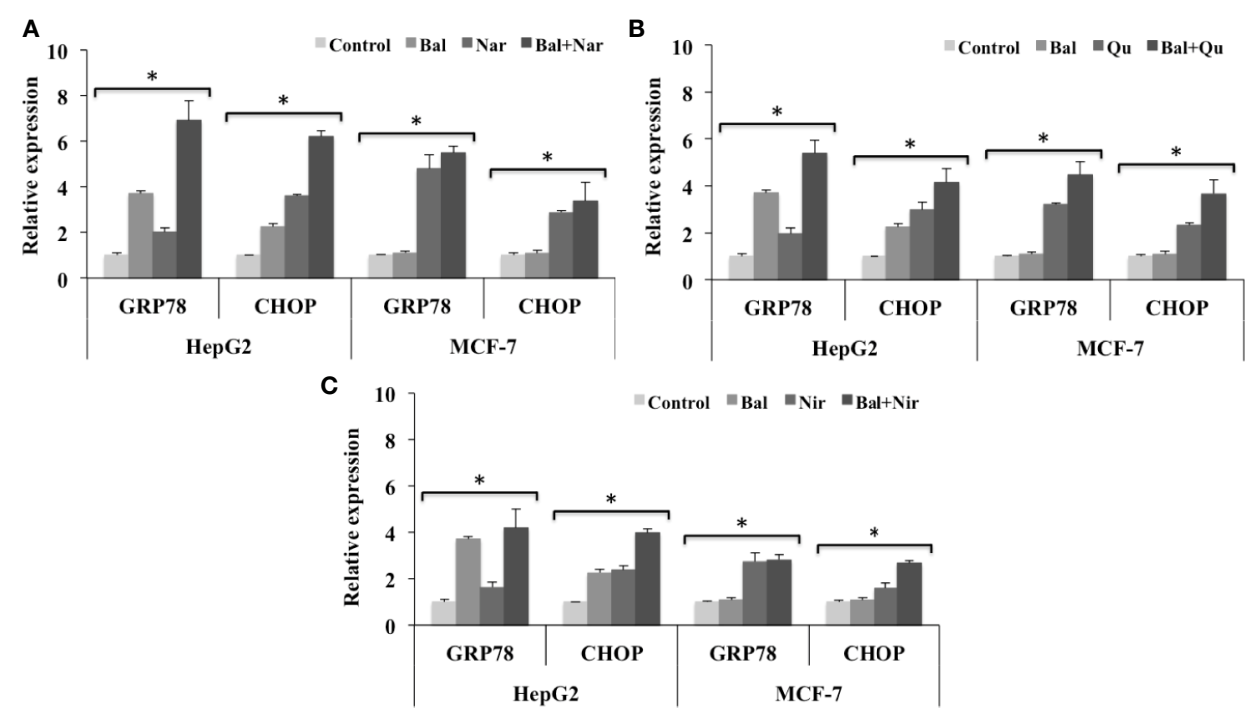

FIGURE 10 | Effect of Bal-Nar (A), Bal-Qu (B) and Bal-Nir (C) on the expression of gene, GRP78 and CHOP, involved in ER-stress mediated apoptosis, compared with Bal in HepG2 and MCF-7 cells. All values are mean \pm SD. SD, standard deviation; $n=3 ;{ }^{*} P<0.05$, Kruskal-Wallis $\mathrm{H}$ test.

HepG2 cells via activating caspase- 8 and caspase- 9 mediated cell death pathways (Arul and Subramanian, 2013; Banjerdpongchai et al., 2016). Qu induced cell death in glioblastoma U373MG cells through proteolytic activation of caspase- 3 and caspase-7, a decrease in mitochondrial membrane potential and increases in caspase-3 and caspase-9 activities (Kim et al., 2013). Our previous studies have demonstrated that Bal also induces apoptosis by increasing the activity of caspase- 3 and -8 in breast cancer cells (Ajji et al., 2017). In this study, Bal in combination with flavonoids (Nar, Nir, and Qu) had an additive effect on caspase- 3 and -8 activity in HepG2 and MCF-7 cells compared to Bal and flavonoids (Nar, Nir, and $\mathrm{Qu}$ ) alone. Out of three combinations, Bal-Nar and Bal-Qu appeared to have a more prominent effect compared to BalNir combination.

Studies have shown that apoptosis is also regulated by the Bcl2 family of pro-apoptotic and anti-apoptotic genes. Flavonoids, such as Nar, Nir, and Qu, have been reported to trigger apoptosis via regulating the expression of pro-apoptotic and anti-apoptotic genes involved in the mitochondrial cell death pathway (Ramos, 2008). Nar isolated from Thymus vulgaris upregulated proapoptotic markers, p18, p19, p21, Bax and Bak, and downregulated anti-apoptotic markers, Cdk4, Cdk6, Cdk7, and $\mathrm{Bcl}-2$ in human colorectal and breast cancer cells leading to apoptosis (Abaza et al., 2015). Qu induced apoptosis in HepG2 hepatoma cells by decreasing the Bcl-XL:Bcl-XS ratio, activating caspase- 3 and -9 and increasing the translocation of Bax to the mitochondrial membrane, leading to mitochondrial mediated apoptosis (Granado-Serrano et al., 2006). Our previous studies demonstrated that Bal induces the mitochondrial cell death pathway in breast cancer cells by increasing the expression of pro-apoptotic genes, Bax, Bid, Bad, and p53, and decreasing the expression of anti-apoptotic genes, $B c l-2$ and $B c l-X L$ (Ajji et al., 2017). In this study, Bal- flavonoid (Nar, Nir, and Qu) treatment tended to increase and appeared to have an additive effect on the expression of Bax, Bid, Bad, and p53 in HepG2 and MCF-7 cells compared to $\mathrm{Bal}$ and flavonoids (Nar, Nir, and $\mathrm{Qu}$ ) treatment alone, where Bal-Nar and Bal-Qu appeared to have more pronounced and additive effect compared to Bal-Nir combination. Increase in activation of caspase- 3 and -8 , upregulation of pro-apoptotic genes (Bax, Bid, Bad, p53) and downregulation of anti-apoptotic genes ( $B c l-2$ and $B c l-X L)$ with Bal-Nar, Bal-Nir and Bal-Qu treatment compared to Bal and flavonoid (Nar, Nir, or Qu) treatment alone in HepG2 and MCF7 cells, suggested that these flavonoids increase Bal-induced mitochondrial mediated apoptosis with a possible additive effect in HepG2 and MCF-7 cells, which could be considered as a promising strategy to sensitize cells to Bal treatment.

The ER stress response has been reported to initiate apoptosis in various cancer cells, through three different pathways; (i) activation of $C H O P$, also known as DNA damage-inducible gene 153 (GADD153), (ii) activation of ER associated caspases and (iii) activation of c-Jun $\mathrm{N}$ - terminal kinase (JNK)-mediated cell death (G Johnson et al., 2011). Qu induced ER-stress-mediated apoptosis by increasing the expression of ATF, GRP78 and CHOP in prostate cancer PC-3 cells (Liu et al., 2014). It has been reported that $\mathrm{Qu}$ pre-treatment elicits ER-stress to enhance cisplatin cytotoxicity in ovarian cancer cells, indicating that $\mathrm{Qu}$ has a potential to enhance the efficacy of cisplatin induced apoptosis in ovarian cancer cells (Yang et al., 2015). Our studies have shown that Bal does not activate ER-stressmediated apoptosis in breast cancer (MCF-7 and BT549) cells (Ajji et al., 2017). However, co-treatment with Bal and flavonoids (Nar, Nir, and $\mathrm{Qu}$ ) tended to increase and appeared to have additive effect on the expression of GRP78 and CHOP in HepG2 cells compared to $\mathrm{Bal}$ and flavonoids (Nar, Nir, and Qu) treatment alone. However, in case of MCF-7 cells, Balflavonoid (Nar, Qu, or Nir) treatment tended to increase the 
expression GRP78 and CHOP with respect to Bal alone, but did not increase significantly with respect to flavonoid (Nar, $\mathrm{Qu}$, and Nir) treatment alone, indicating that the effect was entirely due to the presence of the flavonoid in the combined treatment. It is interesting to note that these flavonoids activate ER-stressmediated apoptosis, an additional apoptotic pathway, in breast cancer MCF-7 cells that is not activated by Bal treatment alone.

A number of studies have reported the bioavailability of flavonoids such as Nar, Qu, and Nir in rats. The plasma concentration of $\mathrm{Nar}$ and $\mathrm{Qu}$ metabolites in rats receiving single meal containing $0.25 \%$ Nar and $0.2 \%$ Qu after $24 \mathrm{~h}$ was found to be $128 \mu \mathrm{M}$ and $51 \mu \mathrm{M}$, respectively. The plasma concentration of Nar and Qu increased till 10-12 h after single feed and decreased thereafter indicating that these flavonoids are efficiently absorbed in rats (Manach et al., 1997; Felgines et al., 2000). Our results suggested that consumption of these flavonoids (Nar, Qu, and Nir) with Bal at selected doses might be beneficial to prevent and treat liver and breast cancer, thus advocating its use as a dietary supplement. It could be a promising therapeutic strategy to sensitize liver and breast cells to Bal treatment, thereby improving its effectiveness in cancer therapy. However, further investigations would be required to evaluate appropriate doses of Bal and flavonoids for alleviating liver and breast cancer in clinical trials.

\section{CONCLUSIONS}

To the best of our knowledge, our study demonstrates for the first time that Bal in combination with flavonoids (Nar, Nir, and $\mathrm{Qu}$ ) enhances apoptotic effects in HepG2 and MCF-7 cells through activation of caspase- 3 and -8 and regulation of proapoptotic and anti-apoptotic genes. These results suggested that

\section{REFERENCES}

Abaza, M. S. I., Orabi, K. Y., Al-Quattan, E., and Rajaa, J. (2015). Growth inhibitory and chemo-sensitization effects of naringenin, a natural flavanone purified from Thymus vulgaris, on human breast and colorectal cancer. Cancer Cell Int. 15 (1), 1. doi: 10.1186/s12935-015-0194-0

Ahamad, M. S., Siddiqui, S., Jafri, A., Ahmad, S., Afzal, M., and Arshad, M. (2014). Induction of apoptosis and antiproliferative activity of naringenin in human epidermoid carcinoma cell through ROS generation and cell cycle arrest. PloS One 9 (10), e110003. doi: 10.1371/journal.pone.0110003

Ajji, P. K., Walder, K., and Puri, M. (2016). Functional Analysis of a Type-I Ribosome Inactivating Protein Balsamin from Momordica balsamina with Anti-Microbial and DNase Activity. Plant Foods Hum. Nutr. 71 (3), 265-271. doi: 10.1007/s11130-016-0555-4

Ajji, P. K., Binder, M. J., Walder, K., and Puri, M. (2017). Balsamin induces apoptosis in breast cancer cells via DNA fragmentation and cell cycle arrest. Mol. Cell. Biochem. 432, 189-198. doi: 10.1007/s11010-017-3009-x

Ajji, P. K. (2017). Functional characterization of a novel ribosome inactivating protein from Momordica balsamina. [PhD thesis] (Victoria, Australia: Deakin University).

Alam, M. A., Subhan, N., Rahman, M. M., Uddin, S. J., Reza, H. M., and Sarker, S. D. (2014). Effect of citrus flavonoids, naringin and naringenin, on metabolic syndrome and their mechanisms of action. Adv. Nutr. 5 (4), 404-417. doi: 10.3945/an.113.005603
Bal with flavonoids (Nar, $\mathrm{Qu}$, and Nir) could be a promising therapeutic strategy to reduce proliferation in breast and liver cancer cells and sensitize cells to Bal treatment. However, the study warrants further investigation to evaluate the efficacy and appropriate doses of Bal and flavonoids for alleviating liver and breast cancer in clinical trials.

\section{DATA AVAILABILITY STATEMENT}

The raw data supporting the conclusions of this article will be made available by the authors, without undue reservation.

\section{AUTHOR CONTRIBUTIONS}

PA conducted experiments, analyzed data, and wrote the manuscript. KW participated in the experimental planning, analyzed the data, and edited the manuscript. MP conceived the study, planned the experiments, analyzed the data, and edited the manuscript. All authors contributed to the article and approved the submitted version.

\section{ACKNOWLEDGMENTS}

PA acknowledges the award of Postgraduate Research Scholarship from Deakin University, Australia. All authors acknowledge that this work has not been published elsewhere except in the form of a PhD thesis (Ajji, 2017) at the Deakin University.

Arul, D., and Subramanian, P. (2013). Naringenin (citrus flavonone) induces growth inhibition, cell cycle arrest and apoptosis in human hepatocellular carcinoma cells. Pathol. Oncol. Res. 19 (4), 763-770. doi: 10.1007/s12253-013-9641-1

Banjerdpongchai, R., Wudtiwai, B., and Khaw-on, P. (2016). Induction of Human Hepatocellular Carcinoma HepG2 Cell Apoptosis by Naringin. Asian Pacific J. Cancer Prevent.: APJCP 17 (7), 3289. doi: 10.14456/apjcp.2016.90

Bharti, S., Rani, N., Krishnamurthy, B., and Arya, D. S. (2014). Preclinical evidence for the pharmacological actions of naringin: a review. Planta Med. 80 (06), 437-451. doi: 10.1055/s-0034-1368351

Chan, S. T., Yang, N. C., Huang, C. S., Liao, J. W., and Yeh, S. L. (2013). Quercetin enhances the antitumor activity of trichostatin A through upregulation of p53 protein expression in vitro and in vivo. PloS One 8 (1), e54255. doi: 10.1371/ journal.pone.0054255

Cook, N., and Samman, S. (1996). Flavonoids-chemistry, metabolism, cardioprotective effects, and dietary sources. J. Nutr. Biochem. 7 (2), 66-76. doi: 10.1016/0955-2863(95)00168-9

Deng, X. H., Song, H. Y., Zhou, Y. F., Yuan, G. Y., and Zheng, F. J. (2013). Effects of quercetin on the proliferation of breast cancer cells and expression of survivin in vitro. Exp. Ther. Med. 6 (5), 1155-1158. doi: 10.3892/etm.2013.1285

Du, G., Lin, H., Wang, M., Zhang, S., Wu, X., Lu, L., et al. (2010). Quercetin greatly improved therapeutic index of doxorubicin against $4 \mathrm{~T} 1$ breast cancer by its opposing effects on HIF- $1 \alpha$ in tumor and normal cells. Cancer Chemother. Pharmacol. 65 (2), 277-287. doi: 10.1007/s00280-009-1032-7

Elmore, S. (2007). Apoptosis: a review of programmed cell death. Toxicol. Pathol. 35) 4, 495-516. doi: 10.1080/01926230701320337 
Erlund, I. (2004). Review of the flavonoids quercetin, hesperetin, and naringenin. Dietary sources, bioactivities, bioavailability, and epidemiology. Nutr. Res. 24 (10), 851-874. doi: 10.1016/j.nutres.2004.07.005

Felgines, C., Texier, O., Morand, C., Manach, C., Scalbert, A., Regerat, F., et al. (2000). Bioavailability of the flavanone naringenin and its glycosides in rats. Am. J. Physiol. Gastrointest. Liver Physiol. 279 (6), 1148-1154. doi: 10.1152/ ajpgi.2000.279.6.G1148

G Johnson, G., C White, M., and Grimaldi, M. (2011). Stressed to death: targeting endoplasmic reticulum stress response induced apoptosis in gliomas. Curr. Pharm. Des. 17 (3), 284-292. doi: 10.2174/138161211795049660

Gibellini, L., Pinti, M., Nasi, M., Montagna, J. P., De Biasi, S., Roat, E., et al. (2011). Quercetin and cancer chemoprevention. Evid. Based Complement. Alternat. Med. 2011, 1-15. doi: 10.1093/ecam/neq053

Granado-Serrano, A. B., Martín, M. A., Bravo, L., Goya, L., and Ramos, S. (2006). Quercetin induces apoptosis via caspase activation, regulation of Bcl-2, and inhibition of PI-3-kinase/Akt and ERK pathways in a human hepatoma cell line (HepG2). J. Nutr. 136 (11), 2715-2721. doi: 10.1093/jn/136.11.2715

Guo, B., Zhang, Y., Hui, Q., Wang, H., and Tao, K. (2016). Naringin suppresses the metabolism of A375 cells by inhibiting the phosphorylation of c-Src. Tumor Biol. 37 (3), 3841-3850. doi: 10.1007/s13277-015-4235-z

Harmon, A. W., and Patel, Y. M. (2004). Naringenin inhibits glucose uptake in MCF-7 breast cancer cells: a mechanism for impaired cellular proliferation. Breast Cancer Res. Treat. 85 (2), 103-110. doi: 10.1023/B:BREA.0000025397.56192.e2

Huang, H. C., Huang, C., Wei, Y. X., Shen, M. C., Tu, Y. H., and Wang, C. C. (2016). Chrysin, abundant in Morinda Citrifolia fruit water-EtOAc extracts, combined with apigenin synergistically induced apoptosis and inhibited migration in human breast and liver cancer cells. J. Agric. Food Chem. 64 (21), 4235-4245. doi: 10.1021/acs.jafc.6b00766

Kaur, I., Yadav, S., Hariprasad, G., Gupta, R. C., Srinivasan, A., Batra, J., et al. (2012). Balsamin, a novel ribosome-inactivating protein from the seeds of Balsam apple Momordica balsamina. Amino Acids 43 (2), 973-981. doi: 10.1007/s00726-011-1162-1

Kaur, I., Puri, M., Ahmed, Z., Blanchet, F. P., Mangeat, B., and Piguet, V. (2013). Inhibition of HIV-1 Replication by Balsamin, a Ribosome Inactivating Protein of Momordica balsamina. PloS One 8 (9), e73780. doi: 10.1371/journal. pone. 0073780

Kelly, G. S. (2011). Quercetin. Altern. Med. Rev. 16 (2), 172-194.

Kim, D. I., Lee, S. J., Lee, S. B., Park, K., Kim, W. J., and Moon, S. K. (2008). Requirement for Ras/Raf/ERK pathway in naringin-induced G1-cell-cycle arrest via p21WAF1 expression. Carcinogenesis 29 (9), 1701-1709. doi: 10.1093/carcin/bgn055

Kim, H., Moon, J. Y., Ahn, K. S., and Cho, S. K. (2013). Quercetin induces mitochondrial mediated apoptosis and protective autophagy in human glioblastoma U373MG cells. Oxid. Med. Cell. Longev. 2013, 1-10. doi: $10.1155 / 2013 / 596496$

Kocyigit, A., Koyuncu, I., Dikilitas, M., Bahadori, F., and Turkkan, B. (2016). Cytotoxic, genotoxic and apoptotic effects of naringenin-oxime relative to naringenin on normal and cancer cell lines. Asian Pac. J. Trop. Biomed. 6 (10), 872-880.

Kuhar, M., Imran, S., and Singh, N. (2007). Curcumin and quercetin combined with cisplatin to induce apoptosis in human laryngeal carcinoma Hep-2 cells through the mitochondrial pathway. J. Cancer Mol. 3, 121-128.

Lewandowska, U., Gorlach, S., Owczarek, K., Hrabec, E., and Szewczyk, K. (2014). Synergistic interactions between anticancer chemotherapeutics and phenolic compounds and anticancer synergy between polyphenols. Postepy Hig. Med. Dosw. (Online) 68, 528-540. doi: 10.5604/17322693.1102278

Li, H., Yang, B., Huang, J., Xiang, T., Yin, X., Wan, J., et al. (2013). Naringin inhibits growth potential of human triple-negative breast cancer cells by targeting $\beta$-catenin signaling pathway. Toxicol. Letts. 220 (3), 219-228. doi: 10.1016/j.toxlet.2013.05.006

Li, R. F., Feng, Y. Q., Chen, J. H., Ge, L. T., Xiao, S. Y., and Zuo, X. L. (2015). Naringenin suppresses K562 human leukemia cell proliferation and ameliorates Adriamycin-induced oxidative damage in polymorphonuclear leukocytes. Exp. Ther. Med. 9 (3), 697-706. doi: 10.3892/etm.2015.2185

Li, J., Dong, Y., Hao, G., Wang, B., Wang, J., Liang, Y., et al. (2016). Naringin suppresses the development of glioblastoma by inhibiting FAK activity. J. Drug Targeting 25 (1), 41-48. doi: 10.1080/1061186X.2016.1184668
Liu, K. C., Yen, C. Y., Wu, R. S. C., Yang, J. S., Lu, H. F., Lu, K. W., et al. (2014). The roles of endoplasmic reticulum stress and mitochondrial apoptotic signaling pathway in quercetin-mediated cell death of human prostate cancer PC-3 cells. Environ. Toxicol. 29 (4), 428-439. doi: 10.1002/tox.21769

Manach, C., Morand, C., Demigne, C., Texier, O., and Regerat, F. (1997). Bioavailability of rutin and quercetin in rats. FEBS Letts. 409 (1), 12-16. doi: 10.1016/S0014-5793(97)00467-5

Nair, H. K., Rao, K. V., Aalinkeel, R., Mahajan, S., Chawda, R., and Schwartz, S. A. (2004). Inhibition of prostate cancer cell colony formation by the flavonoid quercetin correlates with modulation of specific regulatory genes. Clin. Diagn. Lab. Immunol. 11 (1), 63-69. doi: 10.1128/CDLI.11.1.63-69.2004

Niu, G., Yin, S., Xie, S., Li, Y., Nie, D., Ma, L., et al. (2011). Quercetin induces apoptosis by activating caspase- 3 and regulating Bcl-2 and cyclooxygenase-2 pathways in human HL-60 cells. Acta Biochim. Biophys. Sin. 43 (1), 30-37. doi: 10.1093/abbs/gmq107

Park, E. J., and M Pezzuto, J. (2012). Flavonoids in cancer prevention. Anti-Cancer Agents Med. Chem. 12 (8), 836-851. doi: 10.2174/187152012802650075

Puri, M. (2011). Updates on naringinase. structural and biotechnological aspects. Applied Microbiol. Biotechnol. 93 (1), 46-60.

Puri, M., Kaur, I., Perugini, M., and Gupta, R. C. (2012). Ribosome inactivating proteins current status and biomedical applications. Drug Discov. Today 17 (13-14), 774-783.

Puri, M., Kaur, A., Schwarz, W., Singh, S., and Kennedy, J. F. (2011). Molecular characterisation and enzymatic hydrolysis of narigin extracted from kinnow peel waste. Int. J. Biol. Macromol. 48, 58-62.

Ramos, S. (2007). Effects of dietary flavonoids on apoptotic pathways related to cancer chemoprevention. J. Nutr. Biochem. 18 (7), 427-442. doi: 10.1016/ j.jnutbio.2006.11.004

Ramos, S. (2008). Cancer chemoprevention and chemotherapy: dietary polyphenols and signalling pathways. Mol. Nutr. Food Res. 52 (5), 507-526. doi: $10.1002 / \mathrm{mnfr} .200700326$

Ross, S. (2010). Evidence for the relationship between diet and cancer. Exp. Oncol. 32 (3), 137-142.

Sabarinathan, D., Mahalakshmi, P., and Vanisree, A. J. (2011). Naringenin, a flavanone inhibits the proliferation of cerebrally implanted C6 glioma cells in rats. Chem. Biol. Interact. 189 (1), 26-36. doi: 10.1016/j.cbi.2010.09.028

Salehi, B., Fokou, P. V. T., Sharifi-Rad, M., Zucca, P, Pezzani, R., Martins, N., et al. The Therapeutic Potential of Naringenin: A Review of Clinical Trials. Pharmaceuticals. (Basel) 12 (1), 11. doi: 10.3390/ph12010011

Sharma, D., Nijhwan, M., and Puri, M. (2017). "Multifuncational bioactives for cancer therapy," in M. Puri ed. Food Bioactives: Extraction and Biotechnological Applications. Chapter 12. (Springer Press), 299-323.

Srivastava, S., Somasagara, R. R., Hegde, M., Nishana, M., Tadi, S. K., Srivastava, M., et al (2016). Quercetin, a Natural Flavonoid Interacts with DNA, Arrests Cell Cycle and Causes Tumor Regression by Activating Mitochondrial Pathway of Apoptosis. Sci. Rep. 6, 240-249.

Williams, R. J., Spencer, J. P., and Rice-Evans, C. (2004). Flavonoids: antioxidants or signalling molecules? Free Radic. Biol. Med. 36 (7), 838-849. doi: 10.1016/ j.freeradbiomed.2004.01.001

Yang, Z., Liu, Y., Liao, J., Gong, C., Sun, C., Zhou, X., et al. (2015). Quercetin induces endoplasmic reticulum stress to enhance cDDP cytotoxicity in ovarian cancer: involvement of STAT3 signaling. FEBS J. 282 (6), 1111-1125. doi: $10.1111 /$ febs.13206

Zhao, P., Mao, J. M., Zhang, S. Y., Zhou, Z. Q., Tan, Y., and Zhang, Y. (2014). Quercetin induces HepG2 cell apoptosis by inhibiting fatty acid biosynthesis. Oncol. Lett. 8 (2), 765-769. doi: 10.3892/ol.2014.2159

Conflict of Interest: The authors declare that the research was conducted in the absence of any commercial or financial relationships that could be construed as a potential conflict of interest.

Copyright (c) 2020 Ajji, Walder and Puri. This is an open-access article distributed under the terms of the Creative Commons Attribution License (CC BY). The use, distribution or reproduction in other forums is permitted, provided the original author(s) and the copyright owner(s) are credited and that the original publication in this journal is cited, in accordance with accepted academic practice. No use, distribution or reproduction is permitted which does not comply with these terms. 